\title{
Enriquecimento ambiental em roedores utilizados para a experimentação animal: revisão de literatura
}

\author{
Environmental enrichment of rodents utilized for \\ animal experimentation: literature review
}

Lívia Camargo Garbin ${ }^{[a]}$, Rafael Resende Faleiros ${ }^{[b]}$, Luiz Alberto do Lago ${ }^{[c]}$

[a] Médica-veterinária, mestranda em Ciência Animal pelo Departamento de Clínica e Cirurgias Veterinárias da Escola de Veterinária da Universidade Federal de Minas Gerais (UFMG), Belo Horizonte, MG - Brasil, e-mail: livia.garbin@gmail.com

[b] Professor doutor do Departamento de Clínica e Cirurgias Veterinárias da Escola de Veterinária da Universidade Federal de Minas Gerais (UFMG), Belo Horizonte, MG - Brasil, e-mail: faleirosufmg@gmail.com

[c] Professor doutor do Departamento de Clínica e Cirurgias Veterinárias da Escola de Veterinária da Universidade Federal de Minas Gerais (UFMG), Belo Horizonte, MG - Brasil, e-mail: lago@vet.ufmg.br

\section{Resumo}

O enriquecimento ambiental visa a promover um ambiente mais agradável aos animais de laboratório, permitindo que os mesmos consigam expressar seu comportamento natural e obtenham melhores respostas tanto nos aspectos físicos como cognitivos. Isso é interessante não somente pelo bem-estar promovido para o animal, mas também por resultados mais fidedignos nas pesquisas, uma vez que os animais passam a se comportar de maneira mais similar à natural. Contudo, o enriquecimento ambiental implica melhora nas condições vividas pelo animal e não no simples aumento da complexidade do meio baseado em valores antropomórficos. Logo, o entendimento do comportamento da espécie é fundamental para o emprego do enriquecimento eficaz e para a interpretação de resultados experimentais reais.

Palavras-chave: Animais de laboratório. Rato. Camundongo. Enriquecimento ambiental. Bem-estar animal.

\section{Abstract}

Environmental enrichment aims to promote a more pleasant environment for laboratory animals, allowing them to express their natural behavior and improve their physical and cognitive responses. This is interesting not only in terms of animal welfare, but also for more reliable results on research, since the animals tend to behave more naturally. However, environmental enrichment involves improving the conditions experienced by the animal, not simply increasing the complexity of the environment based on anthropomorphic aspects. Therefore, understanding the species'behavior is critical to the effective use of enrichment and for the interpretation of actual experimental results.

Keywords: Laboratory animals. Rat. Mouse. Environmental enrichment. Animal welfare. 


\section{Introdução}

Verifica-se hoje, no Brasil, uma crescente preocupação da sociedade com o bem-estar animal. Fruto da crescente conscientização que a convivência harmônica entre homem e animais pode trazer, amplos benefícios foram desenvolvidos tanto para as pessoas quanto para os animais. 0 bem-estar de um indivíduo é seu estado em relação as suas tentativas de adaptação ao ambiente em que o mesmo se encontra (BROOM; MOLENTO, 2004). Nesse contexto, a pesquisa científica envolvendo experimentação animal tem recebido grande destaque. Enquanto alguns grupos questionam a eficiência técnica do uso de animais de laboratório para desenvolvimento de fármacos a serem utilizados no homem, outros até mesmo acreditam que o uso de animais em pesquisas e ensino, é inaceitável sob o ponto de vista ético. Contudo, a continuidade e mesmo a expansão da experimentação animal parece inabalável graças às constantes melhorias na qualidade e na expectativa de vida da população humana promovidas pelo crescente uso de fármacos e técnicas desenvolvidas com o uso da experimentação animal.

Independente dessas questões, toda a discussão tem sido importante para trazer à tona a necessidade da garantia das melhores condições possíveis de criação e uso aos animais de experimentação e ensino, visando a proporcionar-lhes saúde física e psicológica imprescindível tanto ao seu bem-estar, quanto à condução de pesquisas confiáveis.

0 enriquecimento ambiental objetiva permitir que a espécie expresse seu comportamento natural e auxilie nas necessidades físicas e psicológicas (ARAC, 2004).

A exposição de animais a ambientes enriquecidos há muito tempo tem demonstrado benefícios cognitivos tanto em animais saudáveis quanto enfermos, jovens ou idosos. Esses efeitos foram inicialmente estudados na década de 1960 (DIAMOND, 2001), em que foi observado o maior peso cerebral e maior espessura do córtex em animais estimulados pelo ambiente. Posteriormente, esses estudos visaram a aspectos mais sutis, buscando o envolvimento de fatores como o aumento de neurotransmissores, altos níveis de neurotropinas e alterações nos receptores, além de mudanças comportamentais como maior atividade, melhor memória, redução da agressividade, dentre outros (AMARAL et al., 2008; LEGGIO et al., 2005).
Essas diferenças de comportamento relacionadas a fatores sociais, cognitivos e físicos têm sido alvo de muitos estudos recentes (LEGGIO et al., 2005; AMARAL et al., 2008). Animais que vivem em ambientes com enriquecimento ambiental apresentam mudanças moleculares e morfológicas cerebrais que resultam em melhora no aprendizado e memória. Tais mudanças incluem a neurogênese, o aumento da densidade sináptica e a liberação de fatores neurotrópicos (DIAMOND, 2001; SEGOVIA et al., 2009; WURBEL, 2001).

\section{Enriquecimento Ambiental}

O enriquecimento ambiental é um modelo experimental em que os animais são condicionados a um ambiente que potencializa as interações sociais e desenvolve a estimulação motora e sensorial (SEGOVIA et al., 2009). Esse modelo é baseado em três aspectos: a estrutura ambiental, o aspecto social e atividades que o animal pode realizar no ambiente (ARAC, 2004). A exposição de roedores a uma variedade de estímulos como brinquedos, túneis, rodas de exercício permite que o animal expresse o comportamento natural do roedor. A interação social é importante para os roedores e pode ser realizada ao se permitir contato visual, físico, auditivo ou olfativo com outros animais. A atividade física, por outro lado, é uma oportunidade de estimular também o contato social e a capacidade cognitiva do animal (ARAC, 2004; LAMBERT et al., 2005). Tal prática visa a melhora da função biológica dos animais que residem naquele ambiente (NEWBERRY, 1995).

As modificações ambientais têm sido introduzidas nos ambientes de pesquisas laboratoriais e demonstram estimular o comportamento natural da espécie, permitindo o conhecimento das suas necessidades. Quando os animais são privados desse tipo de ambiente, demonstram sinais de estresse, sofrimento, comportamento anormal e doença. Ao fornecer objetos com os quais o animal possa interagir no ambiente, demonstra maior controle sobre o ambiente em que vive, o que reflete na redução do estresse manifestado (VAN DE WEERD et al., 2002).

As mudanças nas condições ambientais em que os animais vivem levam a conclusões fundamentalmente diferentes sobre a organização de funções específicas cerebrais (WURBEL, 2001). 
Não há padronização ou critério para a utilização do enriquecimento ambiental, e os seus objetivos para o mesmo geralmente são vagos e de difícil interpretação da eficácia do resultado. 0 enriquecimento implica melhora do ambiente, não somente o aumento da complexidade apresentada ao animal, visando ao benefício do animal de alguma forma (NEWBERRY, 1995).

A seguir serão apresentados alguns aspectos com relação à importância do enriquecimento ambiental, bem como as alterações fisiológicas desencadeadas por esse estímulo.

\section{Importância do enriquecimento ambien- tal e a ação do mesmo sobre o roedor}

\section{Enriquecimento ambiental e estresse}

Os diversos graus de estresse resultam na ativação tanto do eixo hipotalâmico-pituitário-adrenal, quanto do simpático-adrenomedular (MARASHI et al., 2003). Estímulos estressantes produzem modificações neuroquímicas e de comportamento associados à função do córtex pré-frontal. Os neurônios dopaminérgicos (da área ventral tegmental com projeções para o córtex pré-frontal) são estimulados pelo estresse. A acetilcolina, por outro lado, parece aumentar a sensibilidade do córtex pré-frontal a estímulos aferentes, desencadeando respostas exacerbadas a estímulos menos intensos. 0 excesso de dopamina pode reduzir os processos cognitivos associados à memória, por meio da ativação excessiva dos receptores D1 (SEGOVIA et al., 2009).

Estímulos estressantes constantes levam os animais a apresentarem comportamentos esteriotipados, ou seja, comportamentos anormais repetitivos sem função óbvia, que podem se elevar a níveis extremos. 0 comportamento esteriotipado pode afetar os resultados de estudos que são baseados no comportamento animal (MARASHI et al., 2003; WURBEL, 2001).

Alguns pesquisadores acreditam que ratos de ambientes enriquecidos sejam menos estressados, mais dóceis e consequentemente mais fáceis de manejar que animais confinados em ambiente padrão. Muitas pesquisas demonstram que em ambientes enriquecidos há a redução da resposta do eixo hipotalâmico-pituitário-adrenal, mediante estímulo estressante. 0 efeito do estresse é modificado de acordo com níveis de acetilcolina e dopamina que são liberados a partir desse estímulo. Animais de ambientes enriquecidos apresentaram, em alguns estudos, reduzida liberação de acetilcolina mediante estresse, reduzindo a sensibilidade a tal estímulo (SEGOVIA et al., 2009; VAN DE WEERD et al., 2002).

Segundo Segovia et al. (2009), nos animais de ambientes enriquecidos, os neurônios da porção ventral medial pré-frontal do córtex são ativados e fazem sinapse com células GABAérgicas intercaladas na amígdala, o que inibe o estímulo positivo ao estresse na porção ventral pré-frontal. Os autores, em sua revisão, também tentam explicar o porquê de ocorrer a redução na liberação de acetilcolina em animais de ambientes enriquecidos mediante estresse e levantam a hipótese de que, ao serem expostos ao estresse, ocorreria a ativação das projeções ventrais do córtex pré-frontal aos neurônios GABAérgicos na base do cérebro que provoca redução da resposta ao estresse dos neurônios colinérgicos. Inclusive, em animais mais velhos que vivem em ambientes enriquecidos, a redução da dopamina mediante estresse pode indicar uma melhor adaptação do animal a esse estímulo.

Isso é demonstrado no experimento de Moncek et al. (2004), no qual os autores também observam a reduzida liberação de acetilcolina, cortisona e adrenalina mediante ao estresse agudo de animais que viviam em ambiente com enriquecimento ambiental. Os autores relataram que esses achados provavelmente ocorreram pelo fato de que, como os animais do ambiente enriquecido eram submetidos a fatores que os estimulavam constantemente, resultando em liberação constante de cortisol, os animais sofriam menor variação e uma adaptação mais rápida a estímulos estressantes repentinos. Tal fato pode ser explicado pela melhor plasticidade cerebral e características emocionais apresentadas pelos animais. Logo, apesar de o cortisol ser tóxico para os neurônios (DIAMOND, 2001), não foram encontradas consequências negativas à saúde dos animais relacionadas ao estresse, levando à conclusão de que a ativação hormonal intermitente foi fisiológica. 0 experimento demonstrou que o ambiente com enriquecimento ambiental representa algo mais próximo ao ambiente natural do animal, influenciando diretamente nas respostas 
aos diferente estímulos empregados durante os experimentos, o que deve ser levado em consideração quando os animais são confinados em ambientes controlados.

Tal visão é compartilhada por Segovia et al., (2009), os quais consideraram que o enriquecimento ambiental reduz a reatividade ao estresse dos sistemas dopaminérgicos e colinérgicos pré-frontais. Em seu trabalho, os autores levantaram a hipótese de que o enriquecimento está relacionado à redução e não ao aumento da liberação de neurotransmissores no córtex pré-frontal.

Ademais, acredita-se que a situação estressante em que os animais de laboratório se encontram poderia ocasionar imunossupressão. Sabe-se que o estresse promove imunossupressão, e já foram encontrados baixos níveis de anticorpos e reduzida resistência às doenças em camundongos confinados. Existem estudos que sugerem um moderado efeito do enriquecimento ambiental sobre a blastogênese durante estresse agudo. Apesar de as mudanças comportamentais dos animais nos ambientes enriquecidos aparentemente serem mais benéficas ao animal, principalmente com relação ao estresse, ainda são necessários mais estudos para se comprovar a relação do enriquecimento com os parâmetros imunológicos do animal (MARASHI et al., 2003).

Há autores que acreditam que, quando os animais criados em ambientes enriquecidos são retirados de seus ambientes, os mesmos conseguem se adaptar melhor a ambientes diferentes quando comparados aos animais criados em ambientes controlados (VAN DE WEERD et al, 2002). Embora outros pesquisadores considerem que os ratos criados em ambientes enriquecidos, quando colocados em ambiente padrão, possam sofrer efeitos adversos (NEWBERRY, 1995).

\section{Enriquecimento ambiental e o potencial} cognitivo e motor dos roedores

Geralmente dois fatores são levados em consideração nos estudos com enriquecimento ambiental: a duração do enriquecimento e a idade dos animais utilizados. Sabe-se que a plasticidade do cérebro está relacionada à idade e à duração do estímulo. Logo, esses fatores estarão relacionados às alterações comportamentais induzidas pelo enriquecimento assim como a duração das alterações, pois parece haver a necessidade de que o estímulo seja empregado durante um determinado tempo, para promover mudanças comportamentais nos animais. Ademais, os animais submetidos a ambientes enriquecidos apresentam potencial cognitivo maior, mesmo quando privados de tal ambiente (AMARAL et al., 2008).

Segundo Lambert et al. (2005), o enriquecimento ambiental pode produzir modificações em áreas do cérebro relacionadas ao aprendizado e à memória, como o hipocampo e o neocórtex. 0 enriquecimento está associado a mudanças neuroquímicas e fisiológicas do cérebro. 0 aumento das ramificações dendrídicas, inclusive nas camadas corticais piramidais II/III e V, sinapses, tamanho neuronal, neurogênese, expressão de mRNA de neurotropina e liberação de neurotransmissores têm sido relacionados ao enriquecimento. Os estímulos resultam no espessamento do córtex dos animais (DIAMOND, 2001; MARASHI et al., 2003). Também já foi observada, em estudos, uma recuperação melhor da isquemia cerebral e maior habilidade em resolver problemas, além de melhor adaptação ambiental e emocional (LEGGIO et al., 2005; MONCEK et al., 2004).

As alterações dendríticas, de acordo com estudos citados por Leggio et al. (2005), são um meio sensível para se verificar as modificações dependentes de experiência que ocorrem no cérebro. Como a superfície dendrídica envolve mais de 95\% das sinapses neuronais, as mudanças nas sinapses podem indicar alterações da arborização dendrídica.

Os receptores 5-HT parecem ter alguma função da plasticidade cerebral, uma vez que agonistas 5-HT influenciam na proliferação celular e proliferação dendrítica (MONCEK et al., 2004). Alguns dos efeitos causados pelo enriquecimento ambiental podem ocorrer frente à ação da serotonina nos receptores 5-HT.

Estudos demonstram que os camundongos dos ambientes controlados exploraram mais quando colocados em ambientes diferentes ao que estavam acostumados, quando comparados aos animais de ambientes enriquecidos, que apresentam maior curiosidade, ao contrário do esperado (AMARAL et al., 2008). Isso provavelmente ocorre por causa da mudança abrupta de ambiente, o que desperta maior curiosidade. Nesse caso, acredita-se que os diferentes estímulos, seu tempo de duração, assim 
como o estresse social podem estar relacionados aos resultados.

A maior parte dos experimentos relacionados ao enriquecimento ambiental promovem uma complexa interação de diferentes fatores sociais e estímulos sensomotores (grandes gaiolas, brinquedos, túneis etc). No trabalho de Lambert et al. (2005), os autores acreditam que o próprio exercício já é responsável por estimular a memória e a capacidade cognitiva, principalmente em animais de idade avançada, e questiona se o simples enriquecimento ambiental seria mais eficaz, uma vez que, em muitos experimentos, estes são utilizados conjuntamente. Os autores ressaltam que, dependendo do exercício físico, ocorre um desenvolvimento central diferente. Por exemplo, nos casos em que o animal precisa superar obstáculos, resulta em aumento na formação de sinapses no córtex cerebral, enquanto que, em exercícios repetitivos, resulta em aumento da densidade vascular no cérebro. Esse aumento das sinapses, especialmente em animais de idade mais avançada reflete em melhor memória espacial, relacionada à maior concentração de sinaptofisinas no hipocampo e córtex fronto-parietal. Esse achado também foi encontrado em animais de ambientes enriquecidos. Isso se deve ao fato de que o cérebro retém certa plasticidade sendo responsivo a estímulos mesmo em idade avançada, o que reduz os riscos de alterações neurodegenerativas (SEGOVIA et al., 2009).

Em contrapartida, no experimento de Leggio et al. (2005), os autores ressaltam que o ambiente enriquecido, e não somente o exercício físico, contribui para o comportamento dos animais. Os autores utilizaram, em seu trabalho muitos objetos que estimularam o potencial cognitivo dos animais, acompanhado dos exercícios e interação social. Em tal experimento, foi indicado o aumento dos níveis de fatores neurotrópicos que otimizam o aprendizado e desempenho mental. Os autores também observaram que as experiências complexas que os animais foram submetidos ainda jovens, modificaram a organização sináptica da terceira camada de neurônios parietais piramidais. 0 melhor desempenho dos animais também poderia estar relacionado ao maior número de contatos neuronais que resultam em uma rede mais complexa. Mais uma vez, os achados sugerem um mecanismo de plasticidade envolvido no processo de reorganização baseado nas mudanças observadas.

0 estímulo ambiental tem demonstrado reduzir as deficiências de memória e aprendizado relacionado à idade avançada em camundongos (LAMBERT et al., 2005). Tal melhora na deficiência de memória foi relacionada ao aumento dos níveis de proteínas pré-sinápticas no hipocampo e neocórtex de camundongos.

Com a idade, ocorre um processo fisiológico de redução das funções cognitivas e motoras. Isso acontece por causa das projeções nervosas para o córtex pré-frontal, e alguns estudos reportam a redução das concentrações de dopamina em animais de idade mais avançada. Estudos ainda demonstraram que em animais que viviam em ambientes enriquecidos, houve mudanças nas concentrações de glutamato e GABA na área CA3 do hipocampo correlacionando com a neurogênese observada nos animais mais velhos (SEGOVIA et al., 2009).

No trabalho de Leggio et al. (2005), foi observado que tanto nos animais que foram submetidos a exercícios quanto nos que foram submetidos a estímulos cognitivos, houve a maior concentração de sinaptofisinas no córtex e hipocampo; porém nos que foram submetidos a exercícios, observou-se melhora na memória. Ademais, os animais mais velhos apresentaram resultados ainda mais promissores que nos mais novos. A importância do estímulo físico mesmo em animais mais velhos também é levantada por Newberry (1995) e Amaral et al. (2008). Assim, conclui-se que o trabalho do estímulo cognitivo isolado pode não ser o suficiente para melhorar a memória dos animais jovens e que o exercício por si só é capaz de promover isso.

Apesar de resultados muitas vezes controversos em relação ao melhor estímulo (físico/cognitivo), visando a promoção do aumento da capacidade cognitiva/motora dos ratos, deve ser ressaltado que os diferentes estímulos contribuem para diferentes alterações neurobiológicas observada nos animais, e que todas devem ser levadas em consideração. Aparentemente, ainda não há um consenso de que haja apenas um único estímulo que seja completamente eficaz na estimulação cognitiva e motora dos ratos. 


\section{Enriquecimento ambiental e lesão central}

Os animais que apresentam algum tipo de lesão nervosa também podem se beneficiar com o enriquecimento ambiental. Entretanto, o período de exposição ao estímulo é muito importante na qualidade dos resultados obtidos uma vez que períodos muito curtos em ambientes enriquecidos não promovem os mesmos resultados que períodos mais prolongados tanto em animais enfermos como sadios (DIAMOND, 2001).

Influência do enriquecimento ambiental no peso dos animais

Na pesquisa de Van de Weerd et al. (2002), foi observado que os ratos do ambiente enriquecido apresentaram maior peso do que os ratos dos ambientes padrão, reafirmando dados de outras pesquisas; que os animais de ambientes enriquecidos ganham mais peso que os de ambientes controlados. Os animais dos ambientes enriquecidos consumiram mais alimento, além de terem mais opções para se manterem aquecidos, uma vez que os objetos são compostos de diferentes materiais. Dessa maneira, a energia consumida poderia ser convertida em ganho de peso, ao invés de usar parte desta para o controle térmico. A forma de enriquecimento ambiental influencia diretamente no comportamento e nos efeitos fisiológicos do animal.

Aparentemente, animais que são criados em ambientes enriquecidos podem apresentar diferentes regulação alimentar e energética (VAN DE WEERD et al., 2002).

Diferenças da influência do enriquecimento ambiental e o sexo do animal

O sexo dos animais parece ser um fator que pode influenciar na resposta ao enriquecimento ambiental. Machos submetidos ao enriquecimento ambiental apresentaram maior espessamento do córtex occipital, enquanto que as fêmeas apresentaram maior espessamento do córtex somatossensor quando submetidas ao mesmo ambiente (DIAMOND, 2001).
Enriquecimento ambiental vs. padronização experimental

Existe controvérsia quanto aos efeitos das diferentes formas de enriquecimento quando da interfêrencia na padronização experimental. Alguns autores acreditam que a padronização ambiental seja importante para promover comparação entre experimentos (VAN DE WEERD et al., 2002). Entretanto, animais que vivem em ambientes enriquecidos podem responder melhor a estímulos adversos do que os animais que vivem em ambientes controlados, uma vez que são mais capazes de expressar seu comportamento natural. Ademais, esses animais geralmente são menos sensíveis a outros estímulos quando comparados a animais de ambientes controlados. Estes últimos demonstram maior sensibilidade, uma vez que seus estímulos sensitivos são restritos nos ambientes controlados, além de apresentarem menor capacidade em aprender. Consequentemente, os animais que são criados em ambientes enriquecidos possuem maior estabilidade psíquica e fisiológica, podendo demonstrar melhores resultados científicos nos experimentos em que são submetidos. Logo, a manutenção de animais de laboratório em ambientes controlados para pesquisas têm sido questionada, uma vez que o ambiente padrão não fornece às demandas necessárias para a espécie, o que resulta em variação dos resultados nas pesquisas (VAN DE WEERD et al., 2002).

Além disso, se o ambiente utilizado providenciar melhores condições para o animal, a variação entre indivíduos possivelmente será menor, resultando em menor número de repetições no uso de animais em experimentação. Muitos estudos demonstraram que o enriquecimento ambiental influencia não somente os meios de mensuração dos parâmetros, mas também a variabilidade do resultado. Contudo, a maior parte dos estudos utilizam diferentes métodos de análise e não focalizam especificamente a variação dos resultados (VAN DE WEERD et al., 2002).

\section{Outras considerações}

Apesar dos diversos resultados positivos relatados com o enriquecimento ambiental, estudos 
têm demonstrado que os métodos utilizados podem, com o tempo, se tornar monótonos, passando a não mais estimular a capacidade cognitiva do animal. A combinação de fatores sociais e a exposição frequente a estímulos novos se mostram necessários para o enriquecimento ter efeito máximo (DIAMOND, 2001).

Apesar dos diversos experimentos citados com resultados promissores, ainda não se pode determinar com certeza quais os fatores que são diretamente melhorados com o emprego do enriquecimento (LEGGIO et al., 2005), porque a individualidade do animal deve ser levada em consideração na variação dos resultados nas pesquisas com enriquecimento (DIAMOND, 2001).

\section{Formas de enriquecimento ambiental}

Para a promoção do enriquecimento ambiental, primeiramente deve ser definido qual o comportamento é desejado ou esperado e como isso irá beneficiar o animal. 0 comportamento anormal está relacionado, geralmente, a condições de estresse, apesar de esta relação entre comportamento esteriotipado e bem-estar não estar muito bem definida (NEWBERRY, 1995).

\section{Alimentação}

Existem muitas formas de enriquecimento ambiental. A forma como os alimentos são fornecidos aos animais é uma delas. 0 oferecimento de uma variedade alimentar pode ser uma forma interessante de se promover o enriquecimento ambiental ao animal, especialmente em espécies com dietas generalizadas, como os roedores. Tal alteração estimula a procura do alimento pelo animal assim como seu "manuseio" e pode melhorar a condição nutricional do animal (NEWBERRY, 1995).

Contudo, uma vez utilizada em laboratórios nas mais diversas pesquisas, a variedade alimentar pode ser inconveniente para um experimento, tanto pela falta de padronização na dieta dos animais, quanto na falta de praticidade na alimentação, o que poderia ser prejudicial à pesquisa.

Curiosamente, ratos que vivem em ambiente enriquecido aparentemente possuem um consumo menor de glicose que animais de ambiente padrão. Isso pode estar relacionado ao melhor aproveitamento da glicose pelos animais de ambiente enriquecido (DIAMOND, 2001).

\section{Enriquecimento social}

O enriquecimento social pode ser uma forma de enriquecimento empregada nos animais submetidos a experimentos. Os camundongos podem ser agrupados com um macho e diversas fêmeas em uma gaiola, para que seja estabelecida a dominância hierárquica. Em alguns casos, os ratos machos podem ficar estressados quando colocados em ambientes enriquecidos, mas em geral se adaptam bem em situações de grupo (ENRICHNMENT STRATEGIESFOR RODENTS IN THE LABORATORY, 2004).

Os ratos machos geralmente apresentam certa agressividade quando colocados em ambientes enriquecidos pela disputa de território, uma vez que os objetos introduzidos no ambiente podem ser interpretados como "fronteiras" entre os territórios impostos pelos machos. As fêmeas, por outro lado, apresentam resultados muito positivos, com bom relacionamento com os outros animais do mesmo ambiente. Inclusive, para se definir se o enriquecimento ambiental é benéfico ou não para os ratos machos, parâmetros fisiológicos não somente comportamentais, devem ser empregados na interpretação dos dados (MARASHI et al., 2003).

No entanto, o excesso de animais em um mesmo ambiente pode ser fator desencadeador de estresse, mas, mesmo assim, parece ser menor em ambientes enriquecidos (DIAMOND, 2001).

\section{Enriquecimento ambiental}

A estrutura física do local onde o animal se encontra é muito importante. 0 acesso a um ambiente com objetos que permitam a interação do animal, de acordo com seu comportamento natural, ou o acesso a um ambiente assim, e a possibilidade de interagir com outros roedores é uma interessante forma de enriquecimento, frequentemente utilizada em experimentos. A presença de um ambiente externo mais agradável estimula os sentidos dos animais, podendo aliviar o seu estresse. No entanto 
a presença de pessoas pode ser um fator estressante para os animais, mais do que um fator de "distração", como é o caso de chimpanzés em zoológicos, que ficam mais estressados quando visualizam turistas (ENRICHNMENT STRATEGIESFOR RODENTS IN THE LABORATORY, 2004; NEWBERRY, 1995).

Muitos objetos são utilizados nas gaiolas dos animais com o objetivo de enriquecer o ambiente. Os brinquedos (barras de metal, cordas, objetos de plástico, etc.) são muito empregados. Contudo, sabe-se que certos objetos podem ter mais valor funcional que outros para os animais, e esses valores também podem modificar de acordo com o grupo exposto a tais objetos. 0 estado motivacional irá variar de acordo com o objeto empregado e a forma em que pode ser utilizado. Os roedores parecem preferir as redes e abrigos nos quais podem se proteger da luz. Os objetos podem distrair as cobaias e reduzir o seu estresse, porém a sua presença não significa que estejam necessariamente enriquecendo o ambiente. Em alguns casos, podem inclusive aumentar a agressividade dos machos, o que é contraindicado em tal método (ARAC, 2004; NEWBERRY, 1995).

Marashi et al. (2003) perceberam que a utilização de objetos foi positiva para a melhora no comportamento manifestado pelos animais. Os animais dos ambientes mais enriquecidos apresentaram melhor resultado que animais de ambientes menos enriquecidos. Os animais, nesses casos, foram mais capazes de controlar e predizer a ocorrência de encontros agressivos, o que é um importante pré-requisito para o estabelecimento do bem-estar.

A eficácia da utilização de música para reduzir o estresse dos animais ainda permanece incerta, graças ao limitado conhecimento bioacústico dos animais e a dificuldade de interpretar os resultados. Inclusive, o fornecimento de música em um ambiente já tumultuado pode piorar o estresse manifestado pelo animal (NEWBERRY, 1995).

Importante ressaltar que, apesar das diversas formas para se enriquecer o ambiente dos animais, a principal preocupação deve ser o bem-estar. $\mathrm{O}$ entendimento inadequado do comportamento da espécie leva ao enriquecimento baseado mais em valores antropomórficos do que na necessidade do animal, contribuindo para um enriquecimento ineficiente e para a interpretação inadequada dos resultados (NEWBERRY, 1995). Logo, o enriquecimento ambiental baseado em estudo sobre o comportamento do roedor é muito importante. A promoção do bem-estar é crucial não somente para o animal, mas para a interpretação correta dos resultados experimentais (MARASHI et al., 2003).

\section{Conclusões}

São muitos os trabalhos que demonstram que o enriquecimento ambiental pode incrementar a qualidade de vida dos animais. Ratos que vivem em ambientes enriquecidos tendem a apresentar comportamento mais semelhante ao natural da espécie. No entanto, há questionamentos em relação à adoção do enriquecimento ambiental porque esse pode influenciar na padronização das pesquisas. Porém, ao expressar comportamento mais semelhante ao natural em ambientes enriquecidos, os animais se tornam aptos a gerar respostas fisiológicas com menor interferência ambiental.

Para o emprego em larga escala do enriquecimento ambiental na experimentação animal, estudos etológicos ainda são necessários para a promoção de um enriquecimento baseado nas necessidades físicas e sociais dos animais e não em aspectos antropomórficos.

\section{Referências}

AMARAL, O. B. et al. Duration of environmental enrichment influences the magnitude and persistence of its behavioral effects on mice. Physiology and Behavior, n. 93, p. 388-394. 2008.

ARAC. Enrichment strategies for rodents in the laboratory. 2004. Disponível em: <http://oacu.od.nih.gov/ wellbeing/RodentEE.pdf> . Acesso em: 20 jun. 2011.

BROOM, D. M.; MOLENTO, C. F. M. Bem-estar animal: conceito e questões relacionadas - revisão. Archives of Veterinary Science, v. 9, n. 2, p. 1-11. 2004.

DIAMOND, M. C. Response of the brain to enrichment. Anais da Academia Brasileira de Ciências, v. 73, n. 2, p. 211-220. 2001.

LAMBERT, T. J.; FERNANDEZ, S. M.; FRICK, K. M. Different types environmental enrichment have discrepant effects on spatial memory and sinaptophysin levels in female mice. Neurobiology of Learning and Memory, v. 83, p. 206-216, 2005. 
LEGGIO, M. G. et. al. Environmental enrichment promotes improve spatial abilities and enhanced dendritic growth in the rat. Behavioral Brain Research, v. 163, p. 78-90. 2005.

MARASHI, V. et al. Effects of different forms of environmental enrichment on behavioral, endocrinological, and immunological parameters in male mice. Hormones and Behavior, v. 43, p. 281-292. 2003.

MONCEK, F. et al. Effects of environmental enrichment on stress related systems in rats. Journal of Neuroendocrinology, v. 16, p. 423-431, 2004.

NEWBERRY, R. C. Environmental enrichment: increasing the biological relevance of captive environments. Applied Animal Behavior Science, v. 44, p. 229-243, 1995.

SEGOVIA, G.; ARCO, A.; MORA, F. Environmental enrichment, prefrontal córtex, stress, and aging of the brain. Journal of Neural Transmission, v. 116, n. 8, p. 10071016. 2009.
VAN DE WEERD, H. et al. Effects of environmental enrichment for mice: variation in experimental results. Journal Applied Animal Welfare Science, v. 5, n. 2, p. 87-109, 2002.

WURBEL, H. Ideal homes? Housing effects on rodent brain and behavior. Trends in Neurosciences, v. 24, n. 4, p. 207-211. 2001.

Recebido: $19 / 01 / 2012$

Received: 01/19/2012

Aprovado: $23 / 10 / 2012$

Approved: 10/23/2012 